\title{
Reduction of Molten Oxide Mixture Containing Iron and Phosphorus Oxide at Temperature below Melting Point of Metallic Iron*
}

\author{
By Minoru SASABE** and Makoto UEHAR $A^{* * *}$
}

\begin{abstract}
Synopsis
The possibility for the production of solid iron containing little phosphorus from molten iron oxide containing phosphorus oxide was examined experimentally.

Molten iron oxide containing phosphorus, lime and silica was reduced by $\mathrm{CO}$ gas in an iron crucible. The samples containing 20 and $60 \%$ $\mathrm{FeO}$ were used as " model" substances for steelmaking slag and iron ore, respectively, in the case of smelting reduction.

Reduction temperature were at 1350 and $1450^{\circ} \mathrm{C}$. Phosphorus contents of produced iron are always below $0.2 \%$. Lower phosphorus content of produced iron can be obtained, with the sample containing $60 \%$ $\mathrm{FeO}$ than with that containing $20 \% \mathrm{FeO}$, with the sample with $\mathrm{CaO} /$ $\mathrm{SiO}_{2}$ ratio of 0.5 than with unity.

The reduction of iron oxide in the sample begins after an incubation period of a few minutes while that of phosphorus oxide in the sample has no incubation period. Namely, at very early stage of the reduction, phosphorus oxide alone is reduced. The reduced phosphorus is diluted with produced iron after beginning of reducing of iron oxide. The content of phosphorus increases again when the reducing rate of the iron oxide decreases.

The reduction rates of oxides of iron and phosphorus can be described as time-linear equations.

It is speculated that the rate determining step of the reduction is the transport process of the substances through the molten oxide.
\end{abstract}

\section{Introduction}

The history of iron- and steelmaking might be a history of a struggle against phosphorus. Some Japanese steel companies are recently making effort to produce steel with phosphorus content of less than $10 \mathrm{ppm}$. It is forecasted on the other hand that phosphorus content in raw material for ironmaking will increase gradually in future because of the exhaustion of iron ore with low phosphorus and the recycle of steelmaking slag. ${ }^{1)}$

The present work is concerned with a method to produce solid iron of low phosphorus content from molten iron oxide with high phosphorus content. The reasons why solid iron is produced from the molten state oxide are as follows:

(1) Solubility of phosphorus in solid iron is much smaller than that in liquid iron.

(2) Produced solid iron particles can coarse easily into large particles in the molten oxide.

This procedure may be classified into a smelting reduction process. A study on the smelting reduction process has begun since about 1930.2) Philbrook and Kirkbride, ${ }^{3)}$ Tarby and Philbrook, ${ }^{4}$ and Shabrin ${ }^{5)}$ studied on the smelting reduction of molten mixture of lime and silica containing small amount of iron oxide. Krainer et al., ${ }^{6)}$ Fan, ${ }^{7)}$ Sugata et al., ${ }^{8)}$ and Davies et al., ${ }^{9)}$ have studied on the smelting reduction of molten mixture of lime and silica containing large amount of iron oxide. Recently Sasaki et al., 10-12) Wijk and Mellberg, ${ }^{13)}$ and Sato $e t$ al. ${ }^{14)}$ have studied in some detail on this process. However these studies are concerned with the process which produces molten iron and molten slag from molten raw material. There have been no sutdy on the process which gives solid iron from molten oxide.

The object of this work is to obtain basic data, i.e., the reduction rate of iron oxide, maximum phosphorus content and physical shape of the produced iron.

\section{Experimental Procedure}

Nominal composition of samples is shown in Table 1. The composition of the sample was decided on the basis of the melting point of the mixed oxide. The samples containing $60 \mathrm{wt} \% \mathrm{FeO}$ were used as " model " substance for iron ore in the case of smelting reduction. The samples containing $20 \mathrm{wt} \% \mathrm{FeO}$ were used as "model" substance for the smelting reduction of steelmaking slag.

The samples were prepared from $\mathrm{Fe}_{2} \mathrm{O}_{3}, \mathrm{SiO}_{2}$, $\mathrm{Ca}(\mathrm{OH})_{2}$ and $\mathrm{P}_{2} \mathrm{O}_{5}$. These were mixed in an alumina mortar and then were melted at about $1500{ }^{\circ} \mathrm{C}$ in a pure iron crucible in air. The molten samples were quenched in water. The distributions of analyzed data of $\mathrm{FeO}$ contents in the quenched samples were scattered within $\pm 3 \%$ due to oxidation of iron crucible. The other compositions were scattered also followed by the scattering of $\mathrm{FeO}$ content. The quenched sample was crushed below 30 mesh pass in a stainless steel mortar.

Experimental apparatus used for the reduction is shown in Fig. 1. The prepared sample of $10 \mathrm{~g}$ was put into a steel crucible. The crucible of $19 \mathrm{~mm}$ in inner-diameter and of $70 \mathrm{~mm}$ in length was hung by steel wire in a mullite tube of $42 \mathrm{~mm}$ in inner-diameter and of $600 \mathrm{~mm}$ in length. Both ends of the mullite tube were closed by stoppers made of silicon rubber. The stopper at the top of the tube was equipped with an inlet for $\mathrm{CO}$ lance of $2 \mathrm{~mm}$ in inner-diameter, an outlet of $\mathrm{CO}$ and $\mathrm{N}_{2}$, and a glass window to observe inside the tube. An inlet of $\mathrm{N}_{2}$ was attached to the stopper at the bottom. A protecting tube for thermocouple was also inserted into the mullite tube through

\footnotetext{
* Presented to the 99th ISIJ Meeting, April 1980, S77, at The University of Tokyo in Tokyo. Manuscript received March 25, 1983. (C) 1984 ISIJ

** Department of Metallurgical Engineering, Chiba Institute of Technology, Tsudanuma, Narashino 275.

*** Formerly Graduate School, Chiba Institute of Technology. Now at Kumamoto Branch, Kyushu Sato Co., Ltd., Tatsudamachi, Kumamoto 862 .
} 
Table 1. Nominal composition of samples. (wt \%)

\begin{tabular}{c|ccccc}
$\begin{array}{c}\text { Sample } \\
\text { No. }\end{array}$ & $\mathrm{FeO}$ & $\mathrm{P}_{2} \mathrm{O}_{5}$ & $\mathrm{CaO}$ & $\mathrm{SiO}_{2}$ & $\begin{array}{c}\mathrm{CaO} / \\
\mathrm{SiO}_{2}\end{array}$ \\
\hline 1 & 60 & 5 & 17.5 & 17.5 & 1.0 \\
2 & 60 & 5 & 11.7 & 23.3 & 0.5 \\
3 & 20 & 5 & 37.5 & 37.5 & 1.0 \\
4 & 20 & 5 & 25.0 & 50.0 & 0.5 \\
\hline
\end{tabular}

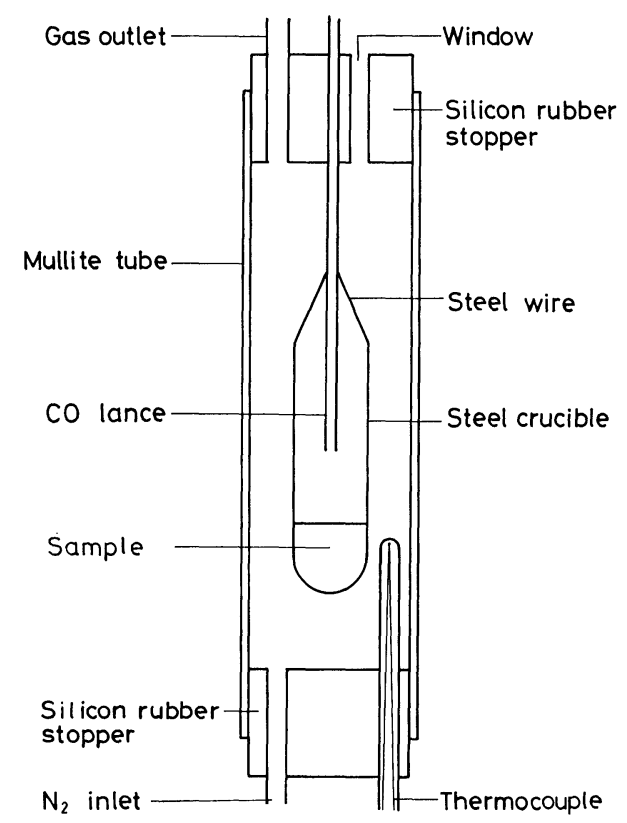

Fig. 1. Schematic illustration of experimental apparatus.

the stopper at the bottom. The mullite tube was heated by a spiral type heating element made of silicon carbide.

The crucible containing crushed sample and the CO lance at room temperature were simultaneously put into the mullite tube heated at experimental temperature. $\mathrm{N}_{2}$ gas was blown into the mullite tube from the bottom at the rate of about 1 (S.T.P.) $l \cdot \min ^{-1}$. After the melting of the sample and returning the temperature in the mullite tube to the experimental temperature, $\mathrm{CO}$ gas was blown on the surface of the molten sample at the rate of 1.5 (S.T.P.) $l \cdot \mathrm{min}^{-1}$. When the flow rate of $\mathrm{CO}$ increased more than 1.5 (S.T.P.) $l \cdot \mathrm{min}^{-1}$, molten sample flowed out from the crucible. Velocity of $\mathrm{CO}$ was about $8 \mathrm{~m} \cdot \mathrm{s}^{-1}$ at the outlet of the nozzle. A distance between the surface of the molten oxide and the nozzle of the lance was about $20 \mathrm{~mm}$.

After the prescribed reduction time, $\mathrm{CO}$ was stopped and $\mathrm{N}_{2}$ was introduced into the mullite tube. And then the CO lance and the crucible were pulled up to the upper part of the mullite tube where temperature was lower. When the sample was cooled to room temperature, the crucible was taken out of the mullite tube and weighed. Degree of reduction of the sample was determined on the basis of its weight decreasing during the reduction. No weight change of the crucible during reduction was confirmed prior to the measurement.
$\mathrm{CO}$ gas was purified over soda lime and silica gel. $\mathrm{N}_{2}$ was dried and deoxidized over silica gel and heated magnesium, respectively.

Experimental temperatures were at 1350 and $1450{ }^{\circ} \mathrm{C}$. Reduction time were varied from 15 to $240 \mathrm{~min}$ at every $15 \mathrm{~min}$ intervals.

After the measurement of weight change, the iron crucible containing the reduced sample was cut longitudinally. And then produced iron metal and residual oxide were simultaneously taken out by means of a hammer and pliers. The sample taken out of the crucible was crushed in a stainless steel mortar. The crushed sample was placed in methanol. The iron was removed by a magnet, thus remaining unreduced part of oxide in methanol. The separated iron was again crushed in the stainless steel mortar and then was treated further by means of the magnet in methanol in order to separate a small amount of the un-reduced oxide containing in the iron. The separation was carried out five times or more.

Phosphorus content of the reduced iron was analyzed by means of a indirect atomic absorption spectrometric analysis combined with the extraction of phosphomolybdic acid. ${ }^{15)}$

\section{Experimental Results}

When GO gas was blown on the molten sample, foam evolution was observed on its surface. Some thick iron films and many thin iron films were produced as shown in Photo. 1 where the films were the surfaces of the foams reduced by CO. Many small iron particles were also produced. Configurations of the reduced sample are shown in Table 2 .

Figures 2 and 3 show relationships between degree of reduction of iron oxide as well as that of phosphorus oxide reduction time. The degrees of reduction of iron oxide, $\left(\% R_{\mathrm{Fe}}\right)$, and of phosphorus oxide, $\left(\% R_{\mathrm{P}}\right)$, are defined as follows:

$$
\begin{aligned}
& \left(\% R_{\mathrm{Fe}}\right) \\
& =\frac{\left\{\frac{16}{72}(\% \mathrm{FeO})+\frac{80}{142}\left(\% \mathrm{P}_{2} \mathrm{O}_{5}\right)\right\} \times \frac{62}{80}\{100-(\% \underline{\mathrm{P}})\}}{\frac{16}{72}(\% \mathrm{FeO}) \times\left[\frac{62}{80}\{100-(\% \underline{\mathrm{P}})\}+\frac{56}{16}(\% \underline{\mathrm{P}})\right]} \\
& \quad \times\left(\% R_{\mathrm{O}}\right) \ldots \ldots \ldots \ldots \ldots \ldots \ldots \ldots \ldots \ldots \ldots \ldots \ldots . . .
\end{aligned}
$$

$\left(\% R_{\mathrm{P}}\right)$

$$
=\frac{\left\{\frac{16}{72}(\% \mathrm{FeO})+\frac{80}{142}\left(\% \mathrm{P}_{2} \mathrm{O}_{5}\right)\right\} \times \frac{56}{16}(\% \underline{\mathrm{P}})}{\frac{80}{142}\left(\% \mathrm{P}_{2} \mathrm{O}_{5}\right) \times\left[\frac{62}{80}\{100-(\% \underline{\mathrm{P}})\}+\frac{56}{16}(\% \underline{\mathrm{P}})\right]}
$$

where, $(\% \mathrm{FeO}),\left(\% \mathrm{P}_{2} \mathrm{O}_{5}\right):$ initial percentages of $\mathrm{FeO}$ and $\mathrm{P}_{2} \mathrm{O}_{5}$ of the sample, respectively

$(\% \mathrm{P}):$ percentage of phosphorus of the produced iron

$\left(R_{0}\right)$ : degree of overall reduction.

The degree of overall reduction is defined as total weight loss of the sample during the reduction dividing 


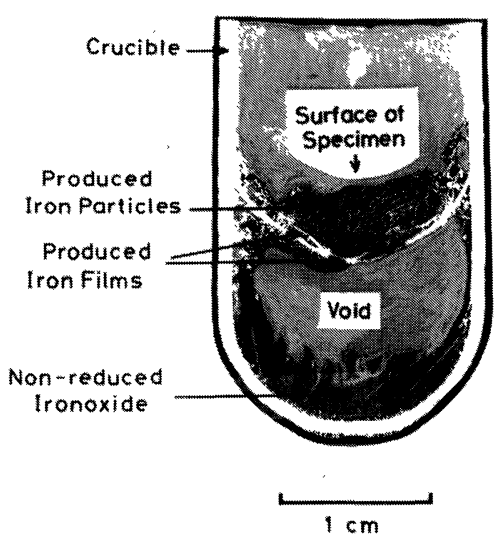

Photo. 1. An example of the longitudinal cross section of the reduced sample. The composition of the sample is $60 \% \mathrm{FeO}$ and ratio of $\mathrm{CaO}$ to $\mathrm{SiO}_{2}$ of unity. The reducing temperature and time are $1450{ }^{\circ} \mathrm{C}$ and 45 min, respectively.

Table 2. Configuration of reduced sample.

\begin{tabular}{c|c|c|c}
$\begin{array}{c}\text { Sample } \\
\text { No. }\end{array}$ & $\begin{array}{c}\text { Reduced } \\
\text { temp. } \\
\left({ }^{\circ} \mathrm{C}\right)\end{array}$ & $\begin{array}{c}\text { Height of } \\
\text { foaming }\end{array}$ & $\begin{array}{c}\text { Distance between } \\
\text { films of produced } \\
\text { iron }\end{array}$ \\
\hline 1 & 1350 & $\begin{array}{l}\text { high } \\
\text { low }\end{array}$ & $\begin{array}{l}\text { wide } \\
\text { narrow }\end{array}$ \\
\hline 2 & 1450 & $\begin{array}{l}\text { high } \\
\text { low }\end{array}$ & $\begin{array}{l}\text { wide } \\
\text { narrow }\end{array}$ \\
\hline 3 & 1450 & $\begin{array}{l}\text { middle } \\
\text { low }\end{array}$ & $\begin{array}{l}\text { chain like } \\
\text { chain like }\end{array}$ \\
\hline 4 & 1450 & $\begin{array}{l}\text { Experiment could not be carried } \\
\text { out. }\end{array}$ \\
\hline
\end{tabular}

by the initial weight of oxygen combining $\mathrm{Fe}$ and $\mathrm{P}$. The samples with the $\mathrm{CaO} / \mathrm{SiO}_{2}$ ratio of unity showed larger reduction rates than that of 0.5 .

Figure 4 shows relationship between phosphorus content of produced iron and degree of reduction of iron oxide. The phosphorus contents were below $0.2 \%$. The phosphorus content decreases at first and afterwards increases with increase of degree of reduction of iron oxide.

Lower phosphorus content of produced iron can be obtained, with the sample containing $60 \% \mathrm{FeO}$ than with that containing $20 \% \mathrm{FeO}$, with the sample with ratio of $\mathrm{CaO}$ to $\mathrm{SiO}_{2}$ of half than that with unity and when it was reduced at $1350^{\circ} \mathrm{C}$ than at $1450^{\circ} \mathrm{C}$.

The experiment using the sample containing $20 \%$ $\mathrm{FeO}$ and with $\mathrm{CaO} / \mathrm{SiO}_{2}$ ratio of 0.5 could not be carried out at $1350^{\circ} \mathrm{C}$ since the sample was mixture of solid and liquid phases at this temperature. When this sample was reduced at $1450^{\circ} \mathrm{C}$, molten iron which was produced from the sample accumulated on the bottom of the crucible. Phosphorus and silicon contents of the molten iron were both more than $1 \%$.

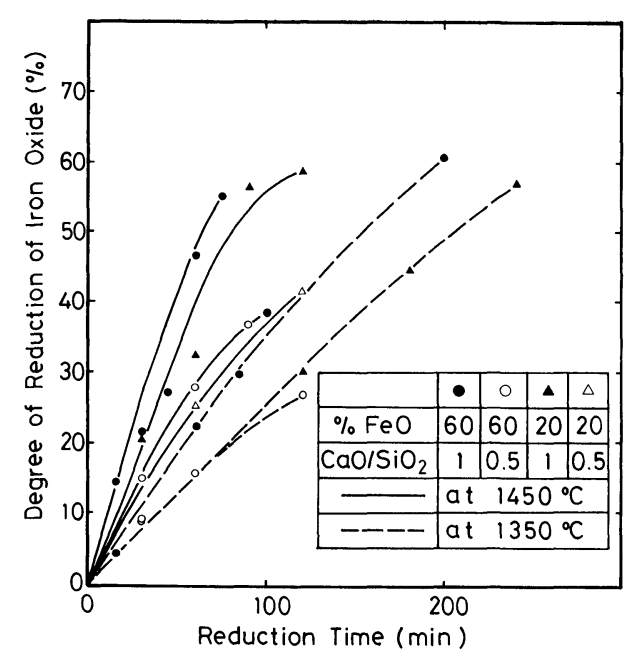

Fig. 2. Relationship between degree of reduction of iron oxide and reduction time.

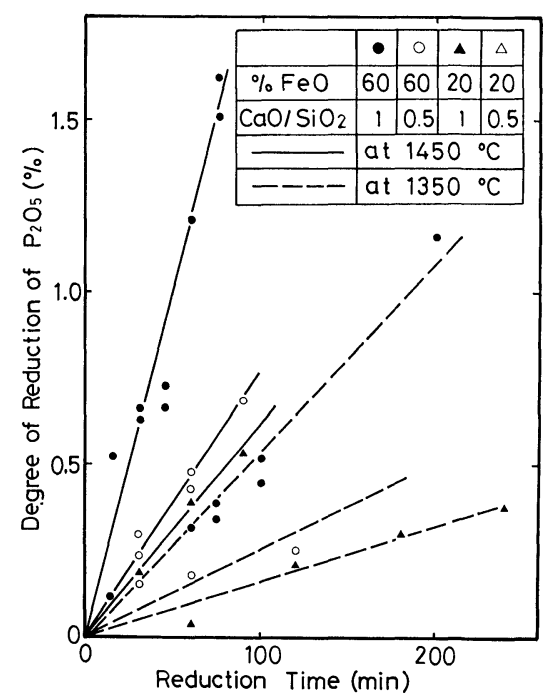

Fig. 3. Relationship between degree of reduction of phosphorus oxide and reduction time.

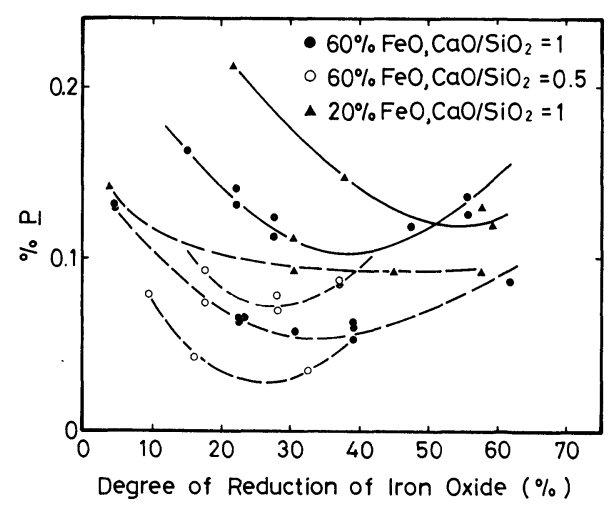

Fig. 4. Relationship between phosphorus content of produced iron, $\% \underline{P}$, and degree of reduction of iron oxide. Solid and dotted lines indicate at 1450 and $1350{ }^{\circ} \mathrm{C}$, respectively.

\section{Discussion}

\section{Rate Determining Step}

The reduction rates of oxides of iron and phosphorus can be described as time-linear equations as shown 
in Figs. 5 and 6, respectively.

The rate equations can be expressed as Eqs. (3) and (4).

For reduction of iron oxide:

$$
-\log \left(1-R_{\mathrm{Fe}}\right)=k_{1} t+A
$$

For reduction of phosphorus oxide:

$$
-\log \left(1-R_{\mathrm{P}}\right)=k_{2} t
$$

where, $R_{\mathrm{Fe}}, \mathrm{R}_{\mathrm{P}}$ : fractional reductions of iron oxide and phosphorus oxide, respectively

$k_{1}, k_{2}$ : rate constants of the reduction of iron oxide and of phosphorus oxide, respectively

$A$ : a constant

Calculated values of $k_{1}, k_{2}, A$ and apparent activation energies, $E$, are listed in Figs. 5 and 6 .

Incubation periods of 5 to $20 \mathrm{~min}$ were observed in the case of iron oxide reduction. The incubation periods are identical when the samples with the same initial iron oxide contents were used at the same temperature. The incubation periods at $1450{ }^{\circ} \mathrm{C}$ are shorter than that at $1350{ }^{\circ} \mathrm{C}$. The samples containing $20 \% \mathrm{FeO}$ showed longer incubation periods than that containing $60 \% \mathrm{FeO}$.

The nearly same rate constant, $k_{1}$, was resulted when the samples with the same $\mathrm{CaO} / \mathrm{SiO}_{2}$ ratio were reduced. The reduction of the sample with $\mathrm{CaO} / \mathrm{SiO}_{2}$ ratio of unity gave larger $k_{1}$ value than that of 0.5. Apparent activation energies were valued between 35 and $43 \mathrm{kcal} \cdot \mathrm{mol}^{-1}$.

On the other hand, no incubation period was seen in the case of reduction of phosphorus oxide. The rate constants of the reduction of phosphorus oxide, $k_{2}$, were varied with reduction temperature, content of iron oxide as well as ratio of $\mathrm{CaO}$ to $\mathrm{SiO}_{2}$. It depends on the iron oxide content of the sample rather than the ratio of $\mathrm{CaO}$ to $\mathrm{SiO}_{2}$. The activation energy data are between $61 \mathrm{kcal} \cdot \mathrm{mol}^{-1}$ and $71 \mathrm{kcal}$. $\mathrm{mol}^{-1}$.

If the reaction can be described by a first order equation, following rate determining steps are conceivable. ${ }^{16)}$

1) Transport process of substance through gas boundary layer.

2) Chemical reaction process at reaction surface.

3) Transport process of substance through either reactant or product.

It is reviewed by Tokuda ${ }^{17}$ ) that the rate determining step of the reduction of molten oxide with high iron oxide content is the transport process of substance through gas boundary layer, although that containing low iron oxide is transport process of iron oxide in molten oxide. However the case 1) is not rate determining step of this experiment because $k_{1}$ and $k_{2}$ did not change when the flow rate of $\mathrm{CO}$ decreased to 1 (S.T.P.) $l \cdot \mathrm{min}^{-1}$. The transport of a substance through produced iron was not the rate determining step, since no substantial increase of $k_{1}$ was observed at $1450{ }^{\circ} \mathrm{C}$ when the produced iron became in a molten state. Thus it is speculated that the rate determining step of reduction of iron oxide

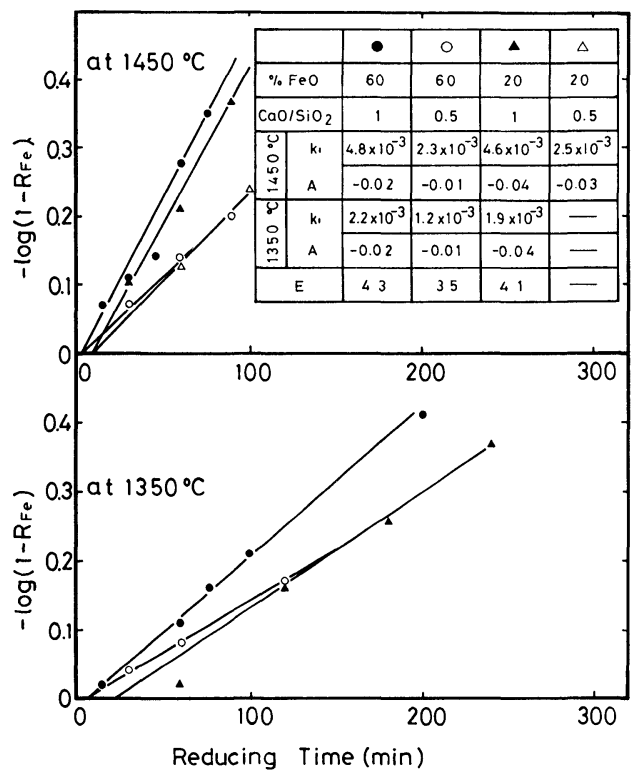

Units in the Table are as follows: Activation energy $E$ : $\mathrm{kcal} \cdot \mathrm{mol}^{-1}$ Rate constant, $k_{1}: \min ^{-1}$

Intersection of ordinate $A$ : dimensionless

Fig. 5. First order equation plot of reducing of iron oxide.

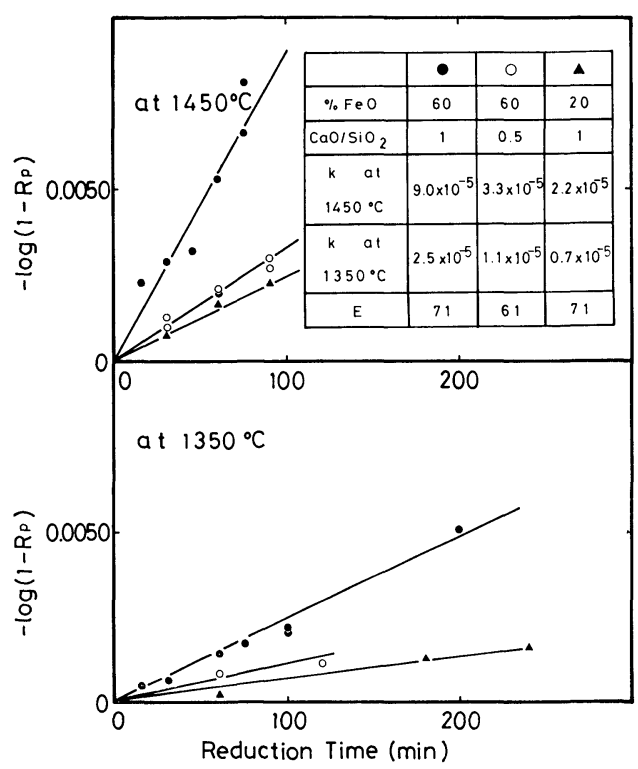

Units in the Table are as follows:

Rate constant, $k_{2}: \min ^{-1}$

Activation energy, $E: \mathrm{kcal} \cdot \mathrm{mol}^{-1}$

Fit. 6. First order equation plot of reducing of phosphorus oxide.

is either the transport process of iron oxide through molten oxide or chemical reaction process at reaction surface. Because there is no example of the rate determining step of the chemical reaction process in the above mentioned review, it is speculated that the most probable rate determining step is the transport process of substance in the molten oxide.

It is also speculated that the rate determining step of the reduction of phosphorus oxide is the transport process of phosphorus oxide through molten oxide.

If the rate determining steps are transport process 
of substances through molten sample, the rate constants might be varied with reducing time because of change of properties of molten sample, especially viscosity, during the reduction. However, viscosity of the molten sample used in the present experiment is almost constant during the reduction unless the degree of reduction is $60 \% \cdot{ }^{18)}$

\section{Relationship between Degree of Reduction of Iron Oxide and Phosphorus Content of Produced Iron}

Phosphorus content of produced iron decreased at first with increase of degree of reduction of iron oxide and then it increased with increase of degree of reduction of iron oxide. In other words, the content decreased with increase of reduction time and then it increased with increase of reduction time. The relationship can be explained by rate equation on the reduction of iron oxide, Eq. (3), and phosphorus oxide, Eq. (4). From both equations,

$$
\begin{aligned}
& R_{\mathrm{Fe}}=1-\frac{1}{B} \exp \left(-2.3 k_{1} t\right) \\
& R_{\mathrm{P}}=1-\exp \left(-2.3 k_{2} t\right) \ldots .
\end{aligned}
$$

where $\log B$ is equal to $A$ in Eq. (3).

$$
\begin{aligned}
(\% \underline{\mathrm{P}})= & {\left[\left\{1-\exp \left(-2.3 k_{2} t\right)\right\} \times 100\right] /[\{1-(1 / B)} \\
& \left.\times \exp \left(-2.3 k_{1} t\right)\right\}+\left\{1-\exp \left(-2.3 k_{2} t\right)\right\}
\end{aligned}
$$

Equation (7) can be rewritten as Eq. (8) since $R_{\mathrm{Fe}} \gg$ $R_{\mathrm{P}}$ as shown in Figs. 2 and 3.

$$
\begin{aligned}
(\% \underline{\mathrm{P}}) \fallingdotseq[\{1 & \left.-\exp \left(-2.3 k_{2} t\right)\right\} /\{1-(1 / B) \\
\times & \left.\left.\exp \left(-2.3 k_{1} t\right)\right\}\right] \times 100 \quad \ldots \ldots \ldots \ldots \ldots \ldots \ldots . .(8) \\
d(\% \underline{\mathrm{P}}) / d t= & 100 B \times\left[\left\{2.3 k_{2} \exp \left(-2.3 k_{2} t\right)\right\}\right. \\
& \times\left\{B-\exp \left(-2.3 k_{1} t\right)\right\}-\left\{2.3 k_{1}\right. \\
& \left.\left.\times \exp \left(-2.3 k_{1} t\right)\right\}\left\{1-\exp \left(-2.3 k_{2} t\right)\right\}\right] / \\
& \left\{B-\exp \left(-2.3 k_{1} t\right)\right\}^{2} \quad \ldots \ldots \ldots \ldots \ldots \ldots \ldots(9)
\end{aligned}
$$

It is difficult to determine the time that gives $d(\% \underline{\mathrm{P}}) / d t$ $=0$. To know whether Eq. (8) has a minimum value or not, signs of $d(\% \underline{\mathrm{P}}) / d t$ should be discussed. For example, the experiment using the sample containing $60 \% \mathrm{FeO}$ and with $\mathrm{CaO} / \mathrm{SiO}_{2}$ ratio of unity, and at $1450{ }^{\circ} \mathrm{C}$ will be discussed, where $k_{1}$ is $5 \times 10^{-3} \mathrm{~min}^{-1}$, $k_{2}$ is $9 \times 10^{-5} \mathrm{~min}^{-1}, A$ is -0.02 and $B$ is 0.955 . When reducing time is $20 \mathrm{~min}$, the sign of $d(\% \underline{\mathrm{P}}) / d t$ is negative. When reducing time is $60 \mathrm{~min}$, the sign is positive. The above discussion shows that Eq. (8) takes a minimum value between $20 \%$ and $50 \%$ of the degree of reduction of iron oxide.

When $B=1$ and $t>0, d(\% \underline{\mathrm{P}}) / d t$ does not become zero. The plots of $\% \underline{\mathrm{P}}$ against time as well as degree of reduction of iron oxide have no minimum value. The incubation period of iron oxide reduction plays an important role in the content of phosphorus of the produced iron. At very early stage of the reduction, phosphorus oxide alone is reduced. The reduced phosphorus is diluted with produced iron after beginning of reducing of iron oxide. The content of phosphorus increases again when the reducing rate of iron oxide decreases. The incubation period has been observed also when solid iron oxide was reduced. ${ }^{19}$ )

\section{Residual Problems on This Method}

There are some problems in this smelting reduction process. One of them is slow reduction rate. Since the maximum reduction rate of iron oxide per crucible is about $40 \% \mathrm{~min}^{-1}$, the rate corresponds to $0.011 \mathrm{~g}$ oxygen $\mathrm{min}^{-1}$ per crucible. When the rate of $0.011 \mathrm{~g}$ oxygen $\min ^{-1}$ per crucible is divided by $\pi$ time the square of inner-radius of the crucible, the rate of $4 \times 10^{-3} \mathrm{~g}$ oxygen $\mathrm{min}^{-1} \cdot \mathrm{cm}^{-2}$, i.e., $2.5 \times 10^{-4} \mathrm{~mol}$. $\mathrm{min}^{-1} \cdot \mathrm{cm}^{-2}$, can be estimated. However, it is impossible to estimate exactly the reduction rate per unit area because of form evolution of the sample. It is sure that the maximum reduction rate per unit area is smaller than $2.5 \times 10^{-4} \mathrm{~mol} \cdot \mathrm{min}^{-1} \cdot \mathrm{cm}^{-2}$. The rate is smaller than reduction rate of molten iron oxide by solid carbon, ${ }^{12)} 3 \times 10^{-3} \mathrm{~mol} \cdot \mathrm{min}^{-1} \cdot \mathrm{cm}^{-2}$.

It is speculated that the difference between two reduction rates is induced by the difference of convection rate of liquid oxide phases. The convection rate during reaction between solid carbon and liquid oxide is larger than that between carbon monoxide and liquid oxide since volume change of gas produced by the solid-liquid reaction is much larger than that by the gas-liquid reaction. This problem will be solved by the device for increasing the convection force and the reaction surface.

Second problem is the separation of residual oxide from produced iron. A superior separation method is expected to be developed.

\section{Summary}

The possibility for the production of solid iron containing little phosphorus from molten iron oxide containing phosphorus oxide at temperature below melting point of iron was examined experimentally.

The experimental results are as follows:

(1) Phosphorus content of produced iron is less than $0.2 \%$ when iron oxide is reduced more than $60 \%$.

(2) The phosphorus content takes a minimum value between $40 \%$ and $50 \%$ of the degree of reduction of iron oxide.

(3) The more the contents of the iron oxide, the lower the $\mathrm{CaO} / \mathrm{SiO}_{2}$ ratio and the lower the temperature, the lower phosphorus content of the produced iron is resulted.

(4) Reaction rates of reduction of iron oxide and phosphorus oxide can be both described by the first order equations.

\section{Acknowledgements}

The authors wish to thank M.E.S. Yamashita, a research associate of Chiba Institute of Technology, for his help for atomic absorption spectrometric analysis. The authors also wish to thank Messrs. Koyashiki, Naoe, Fukunishi, Saito and Kakishima for their experimental assistance as students of Chiba Institute of Technology. 
The research was financially supported by a grantin-aid for scientific research from The Research Committee of Chiba Institute of Technology.

\section{REFERENCES}

1) T. Emi: Stahl u. Eisen, 100 (1980), 998.

2) M. Nakamura and N. Tokumitsu: Tetsu-to-Hagané, 67 (1981), 480

3) W. O. Philbrook and L. D. Kirkbride: J. Metals, (1956), No. 3, 351.

4) S. K. Tarby and W. O. Philbrook: Trans. AIME, 239 (1967), 1005.

5) S. V. Shabrin: Izv. VUZov, Cher. Met., (1976), No. 1, 26.

6) H. Krainer, H. P. Beer and H. Brandl: Tech. Mitt. Krupp Forsch-Ber., 24 (1966), 139.

7) F. Fan: Met. Trans., 1 (1970), 2537.

8) M. Sugata, T. Sugiyama and S. Kondo: Tetsu-to-Hagané, 58 (1972), 1363.

9) M.W. Davies, G.S.F. Hazeldean and P.N. Smith:
Rechardson Conference on Physical Chemistry of Process Metallurgy, ed. by G. R. Belton, London, (July, 1973), 95.

10) Y. Sasaki and T. Soma: Met. Trans., 8B (1977), 189.

11) Y. Sasaki, Y. Okamoto and T. Soma: Tetsu-to-Hagané, 64 (1978), 367.

12) Y. Sasaki and T. Soma: Tetsu-to-Hagané, 64 (1978), 376.

13) O. Wijk and P. O. Mellberg: The 2nd Japan-Sweden Joint Symp. on Ferrous Metallurgy, ed. by ISIJ, ISIJ, Tokyo, (1978), 121.

14) A. Sato, G. Aragane, F. Hirose, R. Nakagawa and S. Yoshimatsu: Tetsu-to-Hagané, 69 (1983), 384.

15) Y. Inokuma and J. Endo: Tetsu-to-Hagané, 63 (1977), 1026.

16) F. Habashi: Principles of Extractive Metallurgy, Gordon and Breach Science Publishers, New York, (1969), 113.

17) M. Tokuda: Handbook of Iron and Steel, I, 3rd Ed., ed. by ISIJ, Maruzen, Tokyo, (1981), 102.

18) Handbook of Physical Properties of Molten Iron and Slags, ed. by ISIJ, ISIJ, Tokyo, (1971), 62.

19) M. Sasabe, K. Goto and M. Someno: Trans. ISIJ, 10 (1971), 25. 